\title{
Sorção e mobilidade do lítio em solos de áreas de disposição final de resíduos sólidos urbanos
}

\author{
Sorption and mobility of lithium in soil areas of final \\ disposition of municipal solid waste
}

\author{
Luiz Fernando Coutinho de Oliveira \\ Bolsista em Produtividade do CNPq; Professor do Departamento de Engenharia da Universidade Federal de Lavras (UFLA) - Lavras (MG), Brasil. \\ Jomara Gonçalves Nogueira \\ Estudante de Graduação em Engenharia Ambiental e Sanitária pela UFLA - Lavras (MG), Brasil.
}

Sthéfanny Sanchez Frizzarim

Estudante de Graduação em Engenharia Ambiental e Sanitária pela UFLA - Lavras (MG), Brasil.

\section{Ronaldo Fia}

Professor do Departamento de Engenharia da UFLA - Lavras (MG), Brasil.

\section{Jéssica Soares Freitas}

Estudante de Graduação em Engenharia Ambiental e Sanitária pela UFLA - Lavras (MG), Brasil.

\section{Fátima Resende Luiz Fia}

Professor do Departamento de Engenharia da UFLA - Lavras (MG), Brasil.

\section{Resumo}

Um dos grandes problemas da atualidade é a disposição inadequada dos resíduos sólidos urbanos no solo, e seus efeitos recaem, principalmente, na contaminação das águas e do solo. Este trabalho objetivou o estudo da sorção e da mobilidade do Lítio nos solos das áreas de disposição de resíduos sólidos urbanos dos municípios de Lavras, Campo Belo e Pouso Alegre, MG. A partir dos ensaios de sorção em batelada e mobilidade do Li em colunas de solo, ajustaram-se os parâmetros das isotermas de Freundlich e da equação de transporte de solutos no solo. Pelos resultados obtidos verificou-se que, dentre os solos avaliados, o do município de Lavras foi o que apresentou a maior mobilidade do Li seguido dos solos de Pouso Alegre e Campo Belo, sendo, portanto, mais vulnerável à contaminação das águas subterrâneas.

Palavras-chave: isoterma de sorção; deslocamento miscível; fator de retardamento; curva de eluição.

\section{Abstract}

A major problem today is the improper disposal of solid waste in the soil, and its effects fall mainly in the contamination of water and soil. This work aimed to study the sorption and mobility of lithium in soil disposal areas of solid waste from Lavras, Campo Belo and Pouso Alegre, Brazil. From the batch sorption tests and Li mobility in soil columns, set up the parameters of the Freundlich isotherms and the equation of solute transport in soil. The results obtained showed that, among the soils evaluated, the city of Lavras showed the increased mobility of Li followed by Pouso Alegre and Campo Belo soils, and are therefore more vulnerable to groundwater contamination.

Keywords: sorption isotherm; miscible displacement; retardation factor; breakthrough curve.

\section{Introdução}

A geração de resíduos sólidos resulta em grave problema ambiental enfrentado pelos grandes centros urbanos. Esses resíduos são uma mistura complexa de materiais orgânicos e inorgânicos com propriedades físicas e químicas variáveis, cujas características acompanham as transformações tecnológicas e marcam o estágio de desenvolvimento de uma sociedade (ANICETO \& 
HORBE, 2012). A preocupação com o meio ambiente e a necessidade de apresentar destino adequado aos resíduos sólidos são aspectos que estão sendo discutidos com frequência, devido principalmente ao descarte de aparelhos celulares em lixões, provocando a contaminação do solo, água e ar (PADILHA et al., 2009). De acordo Piaz e Ferreira (2011), as pilhas e baterias apresentam elementos químicos altamente poluentes tanto ao homem quanto à natureza, dentre os quais destacam-se o Chumbo $(\mathrm{Pb})$, o Mercúrio (Hg), o Cádmio (Cd), o Cobre (Cu), o Níquel (Ni), a Prata (Ag), o Lítio (Li), o Manganês (Mn) e o Zinco (Zn).

Segundo Oliveira e Pasqual (2004), dentre os elementos mais presentes no percolado das áreas de disposição de resíduos sólidos urbanos, destacam-se o $\mathrm{Cd}$, o $\mathrm{Cu}$, o Li e o Zn. Concentrações anômalas de Li podem ocorrer pela introdução direta por meio de descarte de pilhas e baterias juntamente com o lixo comum, ou indiretamente pela incorporação aos aquíferos de espécies químicas que promovam a solubilização de fases minerais que contenham este metal, tais como a matéria orgânica e a diminuição do pH do meio (PROCHNOW; PROCHNOW; LIBERMAN, 2009).

Como produto da biodegradação gerado pela passagem da água através do maciço dos aterramentos dos resíduos sólidos em processo de decomposição, tem-se o líquido chamado de percolado. Esse líquido possui elevada carga de poluentes orgânicos e inorgânicos e, ao entrar em contato com o solo, pode modificar, de forma intensa, suas características físicas, químicas e biológicas, bem como as das águas subterrâneas, caso consiga alcançá-las (OLIVEIRA \& JUCÁ, 2004).

Segundo Korf et al. (2008), o transporte e a retenção de metais em solos de áreas de disposição de resíduos sólidos urbanos já têm sido motivo de estudo por vários autores. Substâncias poluentes presentes no percolado podem estar dissolvidas na água e sujeitas a mecanismos de transporte através do solo, ressaltando que a água é o principal agente transportador de substâncias no perfil do solo. Ao mesmo tempo, o perfil do solo pode servir como meio atenuante de contaminantes que, por meio de processos físicos, químicos e biológicos de interação solo-poluente, alteram a concentração da solução (CELERE et al., 2007).

Segundo PROCHNOW, PROCHNOW E LIBERMAN (2009), as características do percolado dependem da composição, da origem e da idade dos resíduos originalmente dispostos, bem como da fase de decomposição do processo, contendo, em concentrações variadas, compostos orgânicos e elementos traços que possam contaminar o meio ambiente e ser tóxicos aos seres vivos.

Um aspecto fundamental na determinação das quantidades de elementos traços nos solos refere-se a sua movimentação no perfil, que não depende apenas das propriedades físico-químicas do íon metálico, mas também das propriedades físicas e químicas de cada tipo de solo (CAMPOS, 2010). A modelagem da retenção e do transporte de poluentes no solo é uma importante ferramenta para se compreender e simular o movimento desses poluentes no meio poroso e auxiliar na tomada de decisão nas formas de reduzir os impactos ambientais advindos da contaminação do solo e das águas subterrâneas (VINHAL-FREITAS et al., 2010).

No desenvolvimento e na utilização dos modelos, faz-se necessário a caracterização dos processos de sorção dos poluentes pela matriz do solo e a obtenção dos parâmetros das equações que regem o movimento da água e dos poluentes no meio poroso (OLIVEIRA et al., 2010a). Tais modelos são resultantes de soluções da equação do transporte de solutos no solo em relação ao avanço da interface entre o líquido deslocador e o deslocado, e têm como base, o fluxo de massa, a dispersão, a difusão e o retardamento dos solutos (ALCÂNTARA \& CAMARGO, 2010).Sendo assim, o conhecimento do funcionamento hidrodinâmico e hidrodispersivo do solo é de fundamental importância para prevenção e remediação dos danos causados ao meio ambiente, uma vez que o solo é um dos principais destinatários dos resíduos gerados pela sociedade (CARMO et al., 2010).

Embora seja o solo uma barreira natural de proteção aos aquíferos subterrâneos, os fatores que governam sua capacidade em reter elementos traços são extremamente complexos, o que dificulta sobremaneira o seu entendimento e as possibilidades de previsões acerca do comportamento desses elementos, principalmente em longo prazo (OLIVEIRA \& MATTIAZZO, 2001). De acordo com Pierangeli et al. (2007), o efeito poluente dos elementos traços no ambiente depende, principalmente, da capacidade dos colóides do solo em sorvê-los e mantê-los retidos, sendo altamente impactante por persistir no ambiente. A distribuição dos elementos traços nos diversos sítios de adsorção das partículas reativas do solo pode ser usada para estimar a sua disponibilidade ou predizer contaminações do ambiente (KUMMER et al., 2011).

O solo possui grande capacidade de retenção dos elementos traços, porém se esta capacidade for ultrapassada, os metais alterarão sua disponibilidade para o meio (OLIVEIRA et al., 2010b). Portanto, para reduzir o risco potencial de contaminação por compostos nocivos, provenientes da reação de decomposição desses resíduos ao meio, é necessário conhecer as interações com o solo, sua distribuição ao longo do perfil e sua disponibilidade em ambientes de clima tropical e pela capacidade do solo em adsorver esses elementos traços (CORRÊA et al., 2008).

A mobilidade de solutos no solo está inversamente relacionada à sorção dos mesmos à fração sólida ou às condições do meio que favoreçam a precipitação dos íons. A sorção iônica ao complexo de troca do solo faz com que os íons mantenham intercâmbio com a solução do solo, proporcionando ora sua retenção junto à fração sólida, ora sua disponibilização no meio aquoso (TAGLIAFERRO et al., 2011). Em solos intemperizados, a fração argila responsável pela sorção apresenta cargas em sua superfície dependentes do $\mathrm{pH}$, sendo que em ambientes ácidos predominam as carga positivas e em ambientes alcalinos há o predomínio das cargas negativas (CORRÊA et al., 2008). 
Segundo Moreira et al. (2010), a mobilidade do soluto no meio poroso pode ser avaliada por meio de técnicas baseadas na análise do deslocamento miscível e a determinação do fator de retardamento pode ser feita, indiretamente, pelo ensaio de sorção, ou diretamente, pela análise da curva de eluição obtidas em colunas de lixiviação. O fator de retardamento representa a defasagem entre as velocidades de avanço do soluto e a da frente de molhamento da solução percolante, sendo, por essa razão, uma variável de grande importância no estudo do movimento de solutos no solo.

Os métodos empregados no estudo de sorção e na avaliação da mobilidade de solutos no solo, segundo Nicochelli et al. (2012), Chaves e Tito (2011), Castro et al. (2010), Oliveira et al. (2010a; 2010b) são os de batelada e do deslocamento miscível unidimensional em colunas de solo. Os resultados dos ensaios de sorção e deslocamento miscível em colunas de solo, associados a modelos físico-matemáticos, possibilitam entender o comportamento dos solutos no meio poroso e os processos de difusão, dispersão, exclusão aniônica, sorção e mudanças durante o transporte. A maioria das análises da sorção e do transporte de solutos no meio poroso é baseada na aplicação das equações do transporte convectivo-dispersivo e das isotermas de sorção (RIBEIRO et al., 2011 e ASSIS, 2010).

Em vista do exposto, objetivou-se com este trabalho a análise da sorção e da mobilidade do Li em solos de três formas distintas de disposição de resíduos urbanos gerados pelas cidades de Campo Belo, Lavras e Pouso Alegre, com finalidade de identificar a potencialidade de contaminação do solo e das águas subterrâneas em função dos resultados obtidos nos ensaios de sorção e deslocamento miscível.

\section{Metodologia}

Para a realização deste trabalho, foram coletadas amostras deformadas de solo em três áreas de disposição final de resíduos sólidos urbanos (RSU) dos municípios de Campo Belo, Lavras e Pouso Alegre, sob jurisdição da Superintendência Regional de Meio Ambiente e Desenvolvimento Sustentável (Supram) do Sul de Minas Gerais. Em Campo Belo ${ }^{1}$, os resíduos sólidos urbanos são dispostos em um aterro sanitário municipal localizado nas coordenadas geográficas de $20^{\circ} 51^{\prime}$

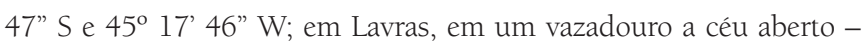
lixão ( $21^{\circ} 16^{\prime} 23^{\prime \prime}$ S e $\left.44^{\circ} 55^{\prime} 34^{\prime \prime} \mathrm{W}\right)$ e em Pouso Alegre ( $22^{\circ} 15^{\prime} 33^{\prime \prime}$ $\mathrm{S}$ e $46^{\circ} \mathrm{W}$ ) em um lixão, o qual foi encerrado a dois anos. Segundo o último censo do $\mathrm{IBGE}^{2}$ a população dos municípios de Pouso Alegre, Lavras e Campo Belo são respectivamente de 132.445, 93.231 e 51.725 habitantes, e a geração diária de resíduos desses municípios, conforme Franco (2012), é de 73,37; 51,65 e 28,66 t.dia-1 ${ }^{-1}$, respectivamente.

Inicialmente, as amostras de solo foram destorroadas e peneiradas com malha de 2,0 mm de abertura e, posteriormente, secas em estufa a $105^{\circ} \mathrm{C}$ para obtenção da TFSE (Terra Fina Seca em Estufa) por um período de $48 \mathrm{~h}$. Após secagem, as amostras foram armazenadas em sacos de polietileno e parte foi encaminhada ao Departamento de Ciência do Solo da Universidade Federal de Lavras para a caracterização química e física, segundo as metodologias preconizadas pela Embrapa (1979).

O potencial de sorção e de lixiviação do Li nos solos estudados foi avaliado pela análise dos valores obtidos para o fator de retardamento e coeficiente de distribuição linear da isoterma de Freundlich. O coeficiente de distribuição linear e o fator de retardamento foram estimados por meio da análise das isotermas de sorção, curvas obtidas a partir de ensaios de equilíbrio em lote que, por sua vez, consistem na agitação de misturas compostas por uma porção de solo e uma solução contendo um contaminante com concentração inicial conhecida. A agitação mantém as partículas sólidas em suspensão, disponibilizando toda sua área ao contato com a solução durante o tempo necessário para que ocorram as reações químicas de interação solo-contaminante. Em seguida, foi feita a separação das fases sólida e líquida e determinou-se a concentração de equilíbrio da solução, sendo que pela diferença entre as concentrações inicial e de equilíbrio obteve-se a concentração do contaminante que foi retida pelo solo (SOUZA; CHAVES; FERNANDES, 2006 e LANGE et al., 2002). Para tal, o elemento traço empregado nos estudos de sorção e deslocamento miscível em laboratório foi o Lítio, obtido de soluções previamente preparadas de Cloreto de Lítio. No ensaio de sorção, foram pesadas em balança de precisão $10 \mathrm{~g}$ de TFSE de cada solo analisado, as quais foram transferidas para beckers em triplicatas e adicionados $15 \mathrm{~mL}$ das soluções de Cloreto de Lítio com concentrações de 1,1; 2,3; 5,2; 10,1; 20,3; 30,1 e 50,0 mg.. $\mathrm{L}^{-1}$ de Li. As concentrações de Li utilizadas nas soluções no estudo da sorção basearam-se na resolução $n^{\circ} 357$ do Conselho Nacional do Meio Ambiente (CONAMA, 2005), para águas doces Classe 1 , que determina a concentração máxima de Li de 2,5 mg. $\mathrm{L}^{-1}$, sendo empregados valores abaixo e acima deste limite para a construção da isoterma de sorção. Os valores das concentrações de Li acima do limite preconizado pela resolução no 357 são justificados pelo fato de que este valor se refere à concentração na água e, como o estudo está sendo realizado no solo, para se alcançar valor de concentração na água subterrânea deve-se ter em mente que parte da quantidade do íon Li aplicada na coluna do solo ficará retida no complexo de troca e parte estará disponível para a lixiviação.

Os beckers contendo os solos e as soluções foram agitados de maneira contínua por um período de 15 minutos e logo após foram colocados em repouso por um período de 48h, para permitir um maior tempo de contato entre a solução e o solo, assim como a decantação da parte sólida. Em seguida, foram coletadas alíquotas de $10 \mathrm{~mL}$ do sobrenadante para a determinação das concentrações do Li em solução e adsorvida ao solo, ou seja:

${ }^{1}$ http://www.feam.br/images/stories/minas_sem_lixoes/2012, acesso disponível em 21de maio de 2012.

${ }^{2} \mathrm{http}: / /$ www.ibge.gov.br/cidadesat, acesso disponível em 21 de maio de 2012 
$C_{s}=\left(C_{i}-C_{f}\right) \frac{V o l}{m}$

em que:

$\mathrm{C}_{\mathrm{s}}$ - concentração de Li adsorvido ao solo ( $\left.\mathrm{mg} \cdot \mathrm{kg}^{-1}\right)$;

$\mathrm{C}_{\mathrm{i}}$ e $\mathrm{C}_{\mathrm{f}}$ - concentração inicial e final de Li em solução (mg. $\mathrm{L}^{-1}$ );

m - massa da TFSE (kg);

Vol- volume da solução adicionada ao becker (L).

A temperatura da solução durante o ensaio de sorção foi mantida em torno de $20^{\circ} \mathrm{C}$, sendo monitorada com o auxílio de um termômetro de infravermelho modelo Minitemp MT4 ${ }^{\circledR}$, fabricado pela Raytek.

Para a determinação da concentração de Li na solução sobrenadante, utilizou-se um fotômetro de chamas de fabricação da Quimis, modelo Q398 ${ }^{\circledR}$. A leitura do fotômetro indica a intensidade do espectro de luz para a determinação da concentração, sendo que para tal faz-se a necessidade de sua calibração. Empregando as concentrações de Li usadas neste trabalho, obteve-se a curva de calibração do equipamento ( $\left.C=1,332 \mathrm{~L}-52,1 ; \mathrm{r}^{2}=0,98\right)$, o que a permitiu a transformação da leitura (L) em concentração (C).

As isotermas de sorção são curvas que representam a concentração de espécie química sorvida pela sua concentração não sorvida a uma temperatura constante, podendo ser ajustado modelos matemáticos utilizados para quantificar a capacidade de sorção de um elemento pelo solo. As equações de Langmuir e Freundlich têm sido utilizadas com frequência para descrever a sorção de diferentes elementos químicos pela fase coloidal do solo (SODRÉ et al., 2001). Segundo Corrêa et al. (2011), a sorção de químicos no solo tem sido mais bem descrita pela isoterma de sorção de Freundlich (Equação 2), sendo a expressão mais comumente utilizada em problemas de contaminação de águas subterrânea.

$\mathrm{C}_{\mathrm{s}}=\mathrm{K}_{\mathrm{f}} \mathrm{C}_{\mathrm{w}}^{\mathrm{N}}$

em que:

$\mathrm{C}_{\mathrm{w}}$ - concentração de Li em solução $\left(\mathrm{mg} \cdot \mathrm{L}^{-1}\right)$;

$\mathrm{K}_{\mathrm{f}}$ e N - coeficiente e expoente da isoterma de Freundlich.

Quando o expoente $\mathrm{N}$ for unitário, tem-se uma isoterma linear que corresponde a um caso especial da isoterma de Freundlich. Neste caso, segundo CORREIA, LANGENBACH E CAMPOS (2010) e D'Agostinho e Flues (2006), o coeficiente de proporcionalidade da isoterma de Freundlich é chamado de coeficiente de partição $\left(\mathrm{K}_{\mathrm{d}}\right)$, ou seja:

$\mathrm{C}_{\mathrm{s}}=\mathrm{K}_{\mathrm{d}} \mathrm{C}_{\mathrm{w}}$

De posse dos resultados dos ensaios de sorção, para os ajustes das isotermas aos modelos potencial e linear, foi empregando o método da minimização da soma dos quadrados dos desvios. Com base no coeficiente angular das isotermas de sorção ajustadas (coeficiente de partição linear), fez-se a determinação dos fatores de retardamento do Li para os diferentes solos, empregando para tal a seguinte expressão:

$\mathrm{R}=1+\frac{\mathrm{D}_{\mathrm{s}}}{\mathrm{P}} \mathrm{K}_{\mathrm{d}}$

em que:

$\mathrm{K}_{\mathrm{d}}$ - coeficiente de distribuição linear;

$\mathrm{P}$ - porosidade total do solo $\left(\mathrm{m}^{3}\right)$;

$\mathrm{D}_{\mathrm{s}}$ - massa específica do solo $\left(\mathrm{kg} \cdot \mathrm{m}^{-3}\right)$.

No ensaio de mobilidade dos elementos traços no solo, empregou-se a metodologia do deslocamento miscível em colunas de solo, conforme descrito por Oliveira et al. (2010a). Para tal, foram preenchidas colunas de solo com a TFSE, empregando anéis de PVC com $5,11 \mathrm{~cm}$ de altura e $5,95 \mathrm{~cm}$ de diâmetro. As colunas foram preenchidas de forma a proporcionar uniformidade e homogeneidade em toda sua extensão, adicionando-se o solo em camadas de aproximadamente $2,0 \mathrm{~cm}$ de espessura até completar o volume da coluna. Cada camada sobreposta foi compactada por leve pressão com um auxílio de um pistilo de cerâmica. Durante o preenchimento das colunas, determinou-se a massa de TFSE utilizada para a determinação da massa específica do solo e da porosidade, ou seja:

$\mathrm{D}_{\mathrm{s}}=\frac{\mathrm{m}_{\mathrm{TFSE}}}{\mathrm{V}_{\mathrm{col}}}$

$P=1-\frac{D_{s}}{D_{p}}$

em que:

$\mathrm{m}_{\text {TFSE }}$ - massa de solo usada no preenchimento da coluna ( $\left.\mathrm{kg}\right)$;

$\mathrm{V}_{\text {col }}$ - volume da coluna de solo $\left(\mathrm{m}^{3}\right)$;

$\mathrm{P}$ - porosidade $\left(\mathrm{m}^{3} \cdot \mathrm{m}^{-3}\right)$;

$\mathrm{D}_{\mathrm{p}}$ - massa específica de partículas $\left(\mathrm{kg} \cdot \mathrm{m}^{-3}\right)$.

As colunas foram colocadas para saturar em bandejas metálicas, de forma que a lâmina de submersão fosse de $2 / 3$ da altura das colunas do solo, permitindo a expulsão do ar contido nos poros. Posteriormente, as colunas foram montadas em um permeâmetro de carga constante, composto de suporte metálico para prender a coluna de solo; anel superior para manter uma carga hidráulica constante; dois frascos de Mariotte, sendo um contendo água deionizada e o outro com a solução deslocadora de Cloreto de Lítio na concentração de 50 mg. $\mathrm{L}^{-1}$ de Li. Inicialmente, aplicou-se às colunas de solo água deionizada para garantir a lixiviação dos íons em solução possivelmente existente no solo. Durante o processo de lixiviação das colunas, fez-se a determinação do fluxo de água que atravessa a coluna do solo, do gradiente de potencial hidráulico, permitindo assim a determinação da condutividade hidráulica do solo saturado por intermédio da aplicação da equação de Darcy que descreve o escoamento em meios porosos. Em seguida, 
foi adicionada a solução deslocadora de Cloreto de Lítio e coletadas alíquotas de aproximadamente $10 \mathrm{~mL}$ da solução eluente com auxílio de provetas, correspondendo a 0,1 do volume total de poros. Para a determinação precisa do volume das alíquotas coletadas, determinou-se a massa da solução coletada com auxílio de balança de precisão e posteriormente fizeram-se a conversão de massa para volume, considerando a massa específica da solução igual $1000 \mathrm{~kg} \cdot \mathrm{m}^{-3}$.

As alíquotas das soluções eluentes coletadas nos ensaios de deslocamento miscível foram armazenadas em recipientes de vidro âmbar com tampas, para posterior determinação da concentração do Li no fotômetro de chamas, permitindo a obtenção dos pontos para o traçado da curva de eluição. Com os resultados do ensaio do deslocamento do Li nas colunas de solo, empregou-se o aplicativo Stanmod, desenvolvido por Simunek et al. (1999), para o ajuste do fator de retardamento (R) e do coeficiente de dispersão hidrodinâmica (D) da solução analítica da equação do transporte de solutos em colunas de solo,obtida por Van Genuchten e Wierenga (1986), ou seja:

$\frac{C}{C_{0}}=\frac{1}{2}\left[\operatorname{erfc}\left(\frac{R L-v t}{\sqrt{4 D R t}}\right)-\left(1+\frac{v L}{D}+\frac{v^{2} t}{D R}\right) e^{\left(\frac{v L}{D}\right)} \operatorname{erfc}\left(\frac{R L+v t}{\sqrt{4 D R t}}\right)\right]+$

$\sqrt{\frac{\mathrm{v}^{2} \mathrm{t}}{\pi \mathrm{DR}}} e^{\left[-\frac{(\mathrm{RL}-\mathrm{vt})^{2}}{4 \mathrm{DRt}}\right]}$

em que:

C - concentração do soluto para qualquer tempo t (mg. $\left.\mathrm{L}^{-1}\right)$;

$\mathrm{C}_{\mathrm{o}}$ - concentração inicial da solução $\left(\mathrm{mg} \cdot \mathrm{L}^{-1}\right)$;

$\mathrm{R}$ - fator de retardamento;

L- comprimento da coluna de solo $(\mathrm{cm})$;

t - tempo de coleta da alíquota da solução deslocadora (h);

D - coeficiente de dispersão hidrodinâmica $\left(\mathrm{cm} \cdot \mathrm{h}^{-1}\right)$;

v - velocidade média da solução deslocadora na coluna de solo $\left(\mathrm{cm} \cdot \mathrm{h}^{-1}\right)$

erfc- função erro complementar.

Para tal, o aplicativo Stanmod foi alimentado com os valores que caracterizam o meio poroso, as concentrações do Li nas alíquotas da solução eluente coletadas no ensaio do deslocamento miscível nas colunas dos solos avaliados, bem como os respectivos tempos de coleta dessas soluções. A partir das informações dos ensaios, o módulo solução inversa do Stanmod ajustou os parâmetros fator de retardamento (R), coeficiente de dispersão hidrodinâmica (D) para as condições de equilíbrio instantâneo (EI) e equilíbrio com um decaimento de primeira ordem (EPO) com o ajuste do coeficiente de transferência de massa de primeira ordem (m).

Com os valores do coeficiente de dispersão hidrodinâmica, velocidade média da solução deslocadora e do comprimento da coluna de solo, calculou-se o número de Peclet (Pe) permitindo, assim, a análise do tipo de fluxo que predominou em cada coluna de solo.

$\mathrm{Pe}=\frac{\mathrm{vL}}{\mathrm{D}}$

Quando Pe $<0,01$, há o predomínio de fluxo difusivoe para Pe $\geq 50$, há predomínio do fluxo dispersivo (KORF et al., 2008). No intervalo entre esses limites ocorrem simultaneamente os fluxos difusivo e dispersivo.

\section{Resultados e Discussão}

NaTabela 1,encontram-seos resultados das análises física e química dos solos de disposição de RSU dos municípios de Campo Belo, Lavras e Pouso Alegre, MG, importantes para a análise da sorção e mobilidade do Li. Pelos resultados obtidos na análise granulométrica, o solo de Pouso Alegre foi classificado como muito argiloso, com $60 \%$ de argila. A princípio pode-se inferir que esse solo terá maior sorção do Li em comparação aos demais solos. Os solos de Campo Belo e Lavras foram classificados, segundo a Embrapa (1979), em argiloso e franco-argiloso, respectivamente.Embora o solo de Pouso Alegre apresente maior quantidade da fração argila, sua capacidade de troca catiônica foi inferior ao solo de Campo Belo, possivelmente por apresentar menor $\mathrm{pH}$, comportamento verificado por Chaves e Tito (2011) e Gonçalves et al. (2008). Com o ambiente acidificado, a liberação de $\mathrm{H}^{+}$propicia uma menor interação de cargas positivas com o solo, contribuindo para a redução do poder de retenção do solo de Pouso Alegre e Lavras. Pela análise dos valores das CTC, segundo a interpretação preconizada pela Embrapa (2006), os solos avaliados apresentam baixa capacidade de retenção de cátions $(1,61<\mathrm{CTC}<4,3)$ e cargas dependentes de $\mathrm{pH}$, como foi verificado por Castro et al. (2010), Alleoni et al. (2005) e Pierangeli et al. (2007), típico de solos tropicais intemperizados. A faixa de $\mathrm{pH}$ encontrada na análise química indicou, segundo Castro et al. (2010),que a acidez fraca a neutra favoreceu a redução da CTC. A baixa CTC do solo de Lavras também foi justificada pela sua baixa quantidade da fração argila. Porém, o solo de Campo Belo, por apresentar um pH mais

Tabela 1 - Análises físicas e químicas dos solos de disposição de RSU dos municípios de Campo Belo, Lavras e Pouso Alegre, MG.

\begin{tabular}{|c|c|c|c|c|c|c|c|c|c|c|}
\hline Município & $\begin{array}{c}\text { Areia } \\
\%\end{array}$ & $\begin{array}{c}\text { Argila } \\
\%\end{array}$ & $\begin{array}{c}\text { Silte } \\
\%\end{array}$ & $\begin{array}{c}D_{p} \\
\mathrm{~kg} \cdot \mathrm{m}^{-3}\end{array}$ & $\frac{D_{s}}{\mathrm{~kg} \cdot \mathrm{m}^{-3}}$ & $\mathrm{~K}_{\mathrm{o}}$ & $\mathrm{pH}$ & $\begin{array}{c}\text { CTC } \\
\text { cmol.dm }{ }^{-3}\end{array}$ & Ki & $\mathrm{Kr}$ \\
\hline Campo Belo & 38 & 43 & 19 & 2660 & 910 & 10,41 & 6,3 & 4,2 & 1,79 & 1,52 \\
\hline Lavras & 30 & 29 & 41 & 2760 & 930 & 1,48 & 5,6 & 2,2 & 1,68 & 1,20 \\
\hline Pouso Alegre & 21 & 60 & 19 & 2710 & 820 & 8,01 & 5,3 & 3,1 & 1,24 & 0,95 \\
\hline
\end{tabular}

$\mathrm{D}_{\mathrm{p}}$ : massa específica de partículas; Ds: massa específica do solo; $\mathrm{K}_{\mathrm{o}}$ : condutividade hidráulica do solo saturado; CTC: capacidade de troca catiônica; Ki e Kr: coeficientes de intemperismo. 
alto em relação aos demais, propiciou uma maior CTC, concordando com os resultados obtidos por Ribeiro et al. (2011), Gonçalves et al. (2008) e Linhares et al. (2008). Segundo esses autores, o pH, a CTC e os teores de óxidos de ferro são os atributos que possuem maior influência sobre a capacidade de adsorção e energia de ligação de elementos traços nos solos.

Para a verificação do maior potencial de retenção de elementos traços nos solos, em especial nos argilosos, faz-se necessário o conhecimento do tipo de argilo-mineral que se encontra presente nos solos avaliados. Os índices Ki e Kr estão diretamente relacionados ao grau de alteração do solo, sendo que, quanto maiores seus valores, menor será o grau de intemperismo. O Ki fornece uma estimativa do grau de intemperismo de solos tropicais e subtropicais apresentando uma estimativa da relação caulinita e gibbsita nos solos. A interpretação do índice Kr é semelhante ao Ki, porém mais apropriado para indicar o grau de alteração dos minerais em solos em que a alta taxa de formação de óxidos de ferro contrasta com os baixos teores de alumina. Pela análise dos coeficientes de intemperismo Ki e Kr obtidos para todos os solos avaliados, maiores que 0,75 (OLIVEIRA et al., 2010a e ALLEONI et al., 2005), indicam a presença mineralógica de argilas do grupo da caulinita, o que justifica os baixos valores de CTC encontrados, conforme verificado também por Pierangeli et al. (2007) e Oliveira et al. (2010b).

Com relação aos atributos físicos (Tabela 1), todos os solos apresentaram valores de condutividade hidráulica do solo saturado entre 0,4 a 18,0 cm.h ${ }^{-1}$, sendo classificados, segundo Gerscovich (2011), como solos de baixa condutividade, embora a porosidade tenha sido elevada (>60\%). A baixa condutividade hidráulica dos solos avaliados refletiu no ensaio do deslocamento da frente de contaminação do Li em colunas de solo, proporcionando um maior tempo de contato da solução deslocadora com a matriz do solo.

$\mathrm{Na}$ Tabela 2,encontram-se os parâmetros ajustados das isotermas de Freundlich para os modelos linear e potencial, bem como os fatores de retardamento (R) obtidos pelo emprego da Equação 4. Para ambos os modelos, observou-se um bom ajuste das isotermas de Freundlich, com coeficientes de determinação $\left(\mathrm{r}^{2}\right)$ próximos de 1,0. Pelos valores ajustados do expoente $\mathrm{N}$ do modelo potencial das isotermas de Freundlich estarem próximos à unidade, não se verificou grandes diferenças entre os coeficientes $\mathrm{K}_{\mathrm{d}}$ e $\mathrm{K}_{\mathrm{f}}$, para o intervalo das concentrações de Li empregadas no ensaio de sorção, o que implica em um comportamento praticamente linear de equilíbrio entre o Li em solução e adsorvido à matriz do solo.Este comportamento das isotermas de sorção se deve ao fato de que o número de sítios de adsorção é muito maior do que a quantidade de moléculas de soluto e a isoterma não exibe um patamar de concentração máxima, resultado semelhante ao encontrado por Oliveira et al. (2010b) e Nicochelli et al. (2012). Os resultados obtidos no ensaio de sorção, validam a estimativa do fator de retardamento (R) pela Equação 4 , que assume na sua formulação uma sorção de equilíbrio linear entre o soluto em solução e fase sólida.

A Figura 1 apresenta os ajustes dos modelos linear e potencial das isotermas de Freundlich para os solos estudados, em que se observa uma diferença no comportamento sortivo do solo de Lavras em relação aos demais em função da menor quantidade da fração argila, responsável pela capacidade de troca catiônica dos solos. Com relação aos solos de

Tabela 2 - Parâmetros ajustados das isotermas linear e potencial de Freundlich e fator de retardamento $(\mathrm{R})$ do Li para os solos de disposição de RSU dos municípios de Campo Belo, Lavras e Pouso Alegre, MG.

\begin{tabular}{|c|c|c|c|c|c|c|c|}
\hline \multirow{3}{*}{ Município } & \multicolumn{7}{|c|}{ Modelos das isotermas de Freundlich } \\
\hline & \multirow{2}{*}{$\mathrm{T}\left({ }^{\circ} \mathrm{C}\right)$} & \multicolumn{2}{|c|}{ Linear } & \multicolumn{4}{|c|}{ Potencial } \\
\hline & & $\mathrm{K}_{\mathrm{d}}$ & $r^{2}$ & $K_{f}$ & $\mathrm{~N}$ & $r^{2}$ & R \\
\hline Campo Belo & 24,9 & 1,906 & 0,999 & 1,871 & 1,011 & 0,999 & 3,64 \\
\hline Lavras & 24,7 & 1,596 & 0,997 & 1,253 & 1,091 & 0,994 & 3,24 \\
\hline PousoAlegre & 25,3 & 1,896 & 0,999 & 1,912 & 0,999 & 0,999 & 3,23 \\
\hline
\end{tabular}

$\mathrm{K}_{\mathrm{d}}$ e $\mathrm{K}_{\mathrm{f}}$ : coeficientes e expoente da isoterma de Freundlich para os modelos linear e potencial; $\mathrm{N}$ : expoente da isoterma de Freundlich para o modelo potencial; $\mathrm{R}$ : fator de retardamento.

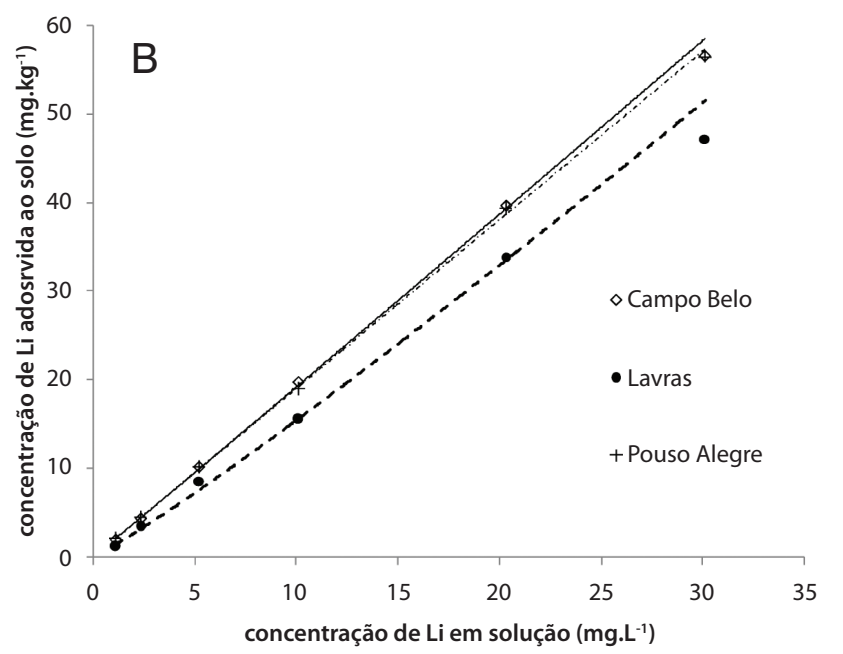

Figura 1 - Modelo linear (A) e potencial (B) da isoterma de Freundlich do Lítio para os solos de Campo Belo, Lavras e Pouso Alegre, MG. 
Campo Belo e Pouso Alegre, não se observou grandes diferenças na sorção do Li por esses solos, uma vez que os valores da CTC encontrados nas análises químicas estarem próximos, comportamento semelhante ao encontrado por Ribeiro et al. (2011), Assis (2010), Castro et al. (2010), Moreira e Alleoni (2010), Oliveira et al. (2010b), Linhares et al. (2009) e Oliveira et al. (2004) avaliando a sorção de elementos traços em diferentes classes de solo. Com relação aos fatores de retardamento (R) obtidos indiretamente (Tabela 2) com base nos parâmetros ajustados das isotermas de sorção lineares (Equação 4), não se verificou grandes diferenças nos valores, o que implica em dizer que, embora existam diferenças na sorção do Li, o retardo do elemento no processo de transporte não promove grandes variações na sua movimentação nos poros do solo. $\mathrm{O}$ fator de retardamento expressa a partição do soluto em solução entre as fases sólida e líquida do solo, e quanto maior o seu valor, menor a disponibilidade do elemento na fase líquida do solo a ser transportado para as camadas mais profundas, reduzindo assim o potencial de contaminação das águas subterrâneas. Os valores de R (Tabela 2) foram elevados, superiores a unidade, implicando que os solos avaliados são bastante reativos no que se referem à sorção do Li, comportamento semelhante verificado por Oliveira et al. (2010b), Linhares et al. (2008), Lange et al. (2002), Martinez et al. (2001), Oliveira e Mattiazzo (2001).

A Tabela 3 apresenta os parâmetros da equação do transporte de solutos ajustados pelo aplicativo Stanmod, considerando as situações de equilíbrio instantâneo (EI) e de equilíbrio com um decaimento de primeira ordem (EPO) entre o Li em solução e a sorção pela matriz do solo. Avaliando a qualidade dos ajustes dos parâmetros da equação do transporte (Tabela 3), observou-se que os coeficientes de determinação $\left(r^{2}\right)$ ficaram próximos de 1,0, conferindo um bom ajuste das curvas de eluição teóricas em relação às experimentais (Figura 2). Com relação às condições de equilíbrio avaliadas (EI e EPO), não se verificou grandes diferenças no ajuste dos parâmetros, podendo assumir, portanto, que houve um equilíbrio instantâneo da concentração do Li na solução deslocadora com a matriz do solo.

$\mathrm{Na}$ Figura 2 verifica-se o comportamento da mobilidade do Li para os solos estudados, o que permitiu inferir sobre a potencialidade dos solos avaliados no que se refere à contaminação das águas subterrâneas. Para uma mesma quantidade de solução que atravessa o meio poroso, verificou-se que o solo de Lavras recupera mais rapidamente a concentração na solução eluente, seguido dos solos de Pouso Alegre e Campo Belo, o que concorda com os resultados obtidos nos ensaios de sorção, ou seja, para 1,0 volume de poros da solução eluente, as concentrações relativas de Li nas alíquotas coletadas representam 70,8; 62,8 e 33,2\% da concentração inicial (Co) para os solos de Lavras, Pouso Alegre e Campo Belo, respectivamente. Para recuperar totalmente a concentração inicial de Li aplicada nas colunas de solo $(\mathrm{C} / \mathrm{Co}=1,0)$, foi necessário o deslocamento dos volumes de solução correspondentes aos volumes de poros de 3,7 para o solo de Campo Belo, 2,8 para o solo de Pouso Alegre e de 2,6 para o solo de Lavras.
Comparando os valores dos fatores de retardamento (R) obtidos diretamente nos ensaios de deslocamento miscível nas colunas dos solos avaliados (Tabela 3) com os obtidos indiretamente nos ensaios de sorção (Tabela 2), observa-se uma grande diferença nos valores de $\mathrm{R}$, comportamento semelhante ao verificado por Oliveira et al. (2010a; 2010b) e Castro et al. (2010). Uma das explicações se deve ao fato de que, nos ensaios de deslocamento da solução de Li nas colunas de solo, teve-se uma condição de dinâmica, envolvendo o escoamento da solução deslocadora no meio poroso reativo, sujeito as processos difusivos, dispersivos e de sorção, conforme verificado por Oliveira et al. (2010a) e Lange et al. (2002). Por outro lado, nos ensaios de sorção, teve-se uma condição de estática, em que, após a agitação da solução de Li em um recipiente fechado, há o repouso do sistema por um tempo de contato superior ao verificado no ensaio de deslocamento, dando assim maior oportunidade de contato da solução com a matriz do solo, e por consequência, maior sorção. Outra possível explicação, segundo Nicochelli et al. (2012), se deve ao fato de que o fator de retardamento obtido considerando o modelo da isoterma linear é uma hipótese simplista do fenômeno da

Tabela 3 - Parâmetros ajustados da equação do transporte do Lítio para os solos de disposição de RSU dos municípios de Campo Belo, Lavras e Pouso Alegre, MG.

\begin{tabular}{lcccccc} 
Parâme- & \multicolumn{2}{c}{ Campo Belo } & \multicolumn{2}{c}{ Lavras } & \multicolumn{2}{c}{ Pouso Alegre } \\
\cline { 2 - 7 } tros & EI & EPO & EI & EPO & EI & EPO \\
$\mathrm{R}$ & 1,328 & 1,328 & 0,733 & 0,731 & 0,826 & 0,834 \\
$\mathrm{D}\left(\mathrm{cm}^{2} \cdot \mathrm{h}^{-1}\right)$ & 48,48 & 48,430 & 3,828 & 3,694 & 22,811 & 18,680 \\
$\mathrm{Pe}$ & 3,157 & 3,157 & 5,309 & 5,502 & 4,904 & 5,989 \\
$\mu\left(\mathrm{h}^{-1}\right)$ & 0,000 & 0,000 & 0,000 & 0,003 & 0,000 & 0,035 \\
$\mathrm{r}^{2}$ & 0,987 & 0,987 & 0,993 & 0,993 & 0,992 & 0,994 \\
\hline
\end{tabular}

El: equilíbrio instantâneo; EPO: equilíbrio com um decaimento de primeira ordem; R: fator de retardamento; D: coeficiente de dispersão hidrodinâmica; Pe: número de Peclet; $\mu$ : coeficiente de transferência de massa de primeira ordem.

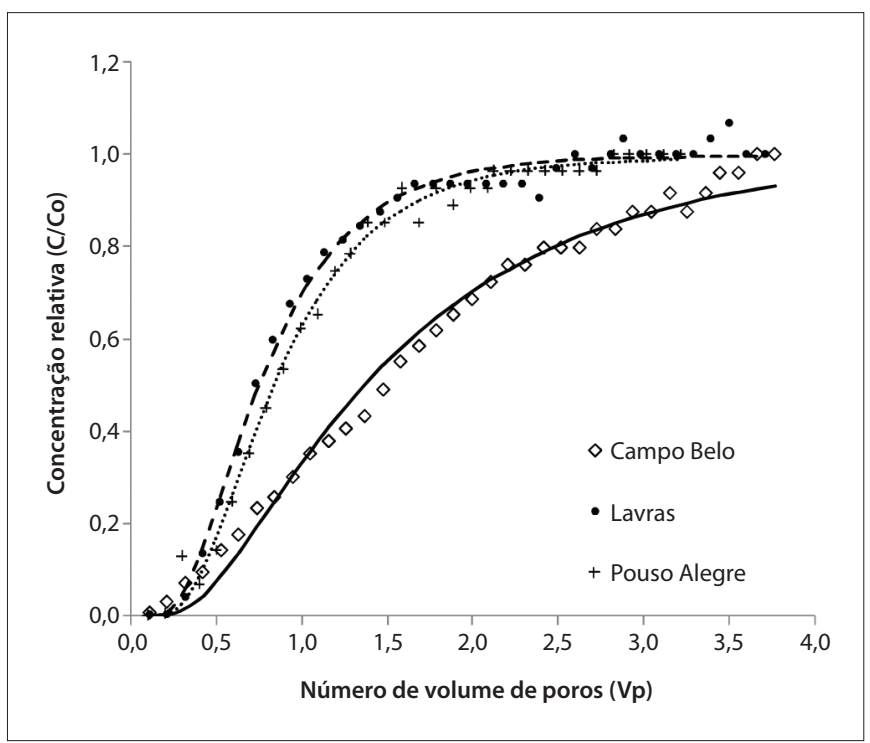

Figura 2 - Curvas de eluição do Li para os solos das áreas de disposição de resíduos sólidos urbanos dos municípios de Campo Belo, Lavras e Pouso Alegre, MG, para a condição de equilíbrio instantâneo. 
sorção, resultando em divergências entre os valores de $\mathrm{R}$ ajustados pela Equação 4 e pelo Stanmod.

Para todos os solos avaliados houve o domínio do fluxo difusivo e dispersivo, com o número de Peclet entre 0,01 $\leq \mathrm{Pe}<50$ para ambas as condições de equilíbrio, EI e EPO. As variações dos valores de Pe obtidas (Tabela 3) se devem às características do meio poroso associadas ao escoamento da solução e à sorção do Li pela matriz do solo. De modo geral, observa-se que o solo de Lavras, em comparação aos demais, apresentou menor CTC e, por consequência, menor fator de retardamento e, devido à baixa velocidade média da solução deslocadora na coluna de solo $\left(\mathrm{v}=3,98 \mathrm{~cm} \cdot \mathrm{h}^{-1}\right)$ e à condutividade hidráulica (Tabela 1), verificou-se menor valor de $\mathrm{D}$ e, portanto, maior Pe, concordando com as afirmações de Lange et al. (2002) e Martinez et al. (2001) de que a defasagem entre as velocidades de avanço do soluto e da solução deslocadora expressa à capacidade do solo na retenção de íons. Por outro lado, para os solos de Campo Belo e Pouso Alegre, que apresentaram maiores valores de $K_{0}$, velocidade média da solução deslocadora na coluna de solo ( $v=29,95$ e $21,89 \mathrm{~cm} \cdot \mathrm{h}^{-1}$, respectivamente) e CTC, os valores de R e D foram superiores ao de Lavras, o que permite inferir que esses solos são mais reativos e por consequente apresentam menores potenciais à lixiviação do Li e à contaminação das águas subterrâneas (Figura 2). Comparando os valores de R obtidos para os solos de Lavras e Pouso Alegre, verificou-se pequena diferença, embora o solo de Pouso Alegre tenha apresentado maior CTC associado à maior quantidade da fração argila, semelhante ao observado por Oliveira et al. (2010a), Lange et al. (2002) e Martinez et al. (2001). Este comportamento pode ser associado ao pHlevemente ácido do solo de Pouso Alegre, promovendo variações das cargas dependentes de $\mathrm{pH}$ nos sítios de troca de carga, diminuindo a CTC e aumentando o tempo de equilíbrio na sorção do Li pela matriz do solo $\left(\mu=0,035 \mathrm{~h}^{-1}\right)$ (Tabela 3 ). Portanto, o solo de Lavras apresenta maior potencialidade de contaminação de águas subterrâneas quando comparado ao demais, com o agravante de que este solo se encontra em uma área de disposição caracterizado como um vazadouro a céu aberto sem nenhuma proteção de fundo de vala. Na sequência, têm-se o solo de Pouso Alegre e Campo Belo, com a ressalva de que em Campo Belo os resíduos sólidos urbanos são depositados em um aterro sanitário, onde existe a impermeabilização de fundo nas plataformas de aterramento com manta de polietileno e o percolado gerado no maciço é encaminhado a um sistema de tratamento composto de um reator anaeróbio de manta de lodo, seguido de lagoas.

\section{Conclusões}

Com base nos resultados obtidos nos ensaios de sorção e deslocamento miscível, verificou-se uma adequação nos ajustes dos parâmetros das isotermas de sorção e da equação do transporte de solutos (fator de retardamento e coeficiente de dispersão hidrodinâmica), permitindo assim a análise da vulnerabilidade dos solos ensaiados quanto à potencialidade de contaminação das águas subterrâneas. A sequência da reatividade dos solos ensaiados quanto à sorção do Li e, em contrapartida, com menores potenciais à contaminação das águas subterrâneas em ordem decrescente foi à seguinte: Campo Belo>Pouso Alegre>Lavras. O solo de Lavras desperta uma maior preocupação por pertencer a uma área de disposição de resíduos sólidos urbanos sem nenhum tipo de proteção quanto à movimentação do Li no solo pelo percolado gerado no maciço de lixo depositado.

\section{Agradecimentos}

À Fundação de Amparo à Pesquisa do estado de Minas Gerais (FAPEMIG) pelo aporte financeiro para a realização deste trabalho.

\section{Referências}

ALCÂNTARA, M.A.K. \& CAMARGO, O.A. (2010). Movimentação de nitrato em horizonte superficial e subsuperficial de latossolo e nitossolo com cargas variáveis. Pesquisa Agropecuária Brasileira, v. 45, n. 1, p. 81-88.

ALLEONI, L.R.F.; IGLESIAS, C.S.M.; MELLO, S.C.; CAMARGO, O.A.; CASAGRANDE, J.C.; LAVORENTI, N.A. (2005). Atributos do solo relacionados à adsorção de cádmio e cobre em solos tropicais. Acta Scientiarum Agronomy, v. 27, n. 4, p. 729-737.

ANICETO, K.C.P. \& HORBE, A.M.C. (2012). Solos urbanos formados pelo acúmulo de resíduos em Manaus, Amazonas, Brasil. Acta Amazônica, v. 42 , n. 1, p. 135-148,
ASSIS, I.R. Adsorção e disponibilidade de arsênio em solos com diferentes composições mineralógicas. 2010, 73 f. Tese (Doutorado em Solos e Nutrição de Plantas) - Universidade Federal de Viçosa, Viçosa, 2010.

CAMPOS, M.C.C. (2010). Atributos dos solos e riscos de lixiviação de metais pesados em solos tropicais. Ambiência - Revista do Setor de Ciências Agrárias e Ambientais, v. 6, n. 3, p. 547-565.

CARMO, A.I.; ANTONINO, A.C.D.; NETTO, A. M.; CORRÊA, M.M. (2010). Caracterização hidrodispersiva de dois solos da região irrigada do Vale do São Francisco. Revista Brasileira de Engenharia Agrícola e Ambiental, v. 14, n. 7, p. 698-704 
CASTRO, M.L.L.; BORGES, J.D.; OLIVEIRA, L.F.C.; RODRIGUES, C.; FIGUEIREDO, C.C.; CASTRO, W.J. (2010). Sorção de cromo em solos do cerrado goiano, Brasil. Ambi-Água, v. 5, n. 2, p. 133-143.

CELERE, M.S.; OLIVEIRA, A.S.; TREVILATO, T.M.B.; SEGURA-MUNHÕZ, SI. (2007). Metais presentes no chorume coletado no aterro sanitário de Ribeirão Preto, São Paulo, Brasil e sua relevância para saúde pública. Caderno de Saúde Pública, v. 23, n. 4, p. 939-947.

CHAVES, L.H.G. \& TITO, G.A. (2011). Cadmium and copper adsorption on bentonite: effects of $\mathrm{pH}$ andparticle size.Revista Ciência Agronômica, v. 42, n. 2 , p. $278-284$

CONAMA - Conselho Nacional do Meio Ambiente. Resolução no 357. Brasília: DOU nº 053, 2005, p. 58-63.

CORRÊA, J.C.; BÜLL, L.T.; PAGANINI, W.S.; GUERRINI, I.A. (2008). Disponibilidade de metais pesados em latossolo com aplicação superficial de escória, lama cal, lodos de esgoto e calcário. Pesquisa Agropecuária Brasileira, v. 43, n. 3, p. 411-419.

CORRÊA, R.M.; NASCIMENTO, C.W.A.; ROCHA, A.T. (2011). Adsorção de fósforo em dez solos do Estado de Pernambuco e suas relações com parâmetros físicos e químicos. Acta Scientiarum Agronomy, v. 33, n. 1, p. 153-159.

CORREIA, F.V.; LANGENBACH, T.; CAMPOS, T.M. (2010). Avaliação do transporte de atrazina em solos sob diferentes condições de manejo agrícola. Revista Brasileira de Ciência do Solo, v. 34, n. 2.

D'AGOSTINHO, A. \& FLUES, M. (2006). Determinação do coeficiente de distribuição $(K d)$ de benzo(a)pireno em solo por isotermas de sorção. Química Nova, v. 29, n. 4, p. 657-661.

EMBRAPA - Empresa Brasileira de Pesquisa Agropecuária. Centro Nacional de Pesquisa de Solos. Manual de métodos de análise de solos. 2 ed. Rio de Janeiro: EMBRAPA, 1997. 212p.

EMBRAPA - Empresa Brasileira de Pesquisa Agropecuária. Centro Nacional de Pesquisa de Solos. Sistema brasileiro de classificação de solos. 2 ed. Brasília: Embrapa. Produção de Informações; Rio de Janeiro: Embrapa Solos, 2006. 306p.

FRANCO, C.S. Caracterização gravimétrica dos resíduos sólidos domiciliares e percepção dos hábitos de descarte no sul de Minas. 2012, 157f. Dissertação (Mestrado em Recursos Hídricos em Sistemas Agrícolas) - Universidade Federal de Lavras, Lavras, 2012.

GERSCOVICH, D.M.S. Fluxo em solos saturados. Rio de Janeiro: UERJ, 2011, 169p.

GONÇALVES, V.C.; CARVALHO, S.A.; TATSCH, F.R.P.; SANTOS NETO, O.A.; MEURER, E.J. (2008). Adsorção de cádmio em solos cauliníticos. Revista da FZVA, v. 15, n. 2, p. 1-10.

KORF, E.P.; MELO, E.F.R.Q.; THOMÉ, A.; ESCOSTEGUY, P.A.V. (2008). Retenção de metais em solo da antiga área de disposição de resíduos sólidos urbanos de Passo Fundo, RS. Revista de Ciências Ambientais, v. 2 , n. 2 , p. $43-60$.

KUMMER, L.; MELO, V.F.; BARROS, Y.J.; AZEVEDO, J.C.R. (2011). Extrações sequenciais de chumbo e zinco em solos de área de mineração e metalurgia de metais pesados. Revista Brasileira de Ciência do Solo, v. 35, p. 2005-2018.

LANGE, L.C.; SIMÕES, G.F.; FERREIRA, C.F.A.; COELHO, H.M.G. Estudo do transporte de contaminantes em meios porosos aplicado a aterros de disposição de resíduos sólidos urbanos. In: CASTILHOS JUNIOR, A.B.; LANGE, L.C.; GOMES, L.P.; PESSIN, N. Alternativas de disposição de resíduos sólidos urbanos para pequenas comunidades.1 ed. Rio de Janeiro: RiMa, ABES, 2002, p-85-92.

LINHARES, L.A.; EGREJA FILHO, F.B.; IANHEZ, R.; SANTOS, E.A. (2008). Aplicação dos modelos de Langmuir e Freundlich na adsorção de cádmio e chumbo em diferentes classes de solos brasileiros. Revista Tecnológica, v. 17, p. 49-60.

LINHARES, L.A.; EGREJA FILHO, F.B.; OLIVEIRA, C.V.; BELLIS, V. (2009). Adsorção de cádmio e chumbo em solos tropicais altamente intemperizados. Pesquisa Agropecuária Brasileira, v. 44, n. 3, p. 291-299.

MARTINEZ, M.A.; RAMOS, V.B.N.; MATOS, A.T.; OLIVEIRA, R.A.; COSTA, S.N. (2001). Influência da competição catiônica nos valores de fator de retardamento e coeficiente de dispersão-difusão de zinco e cobre no solo. Revista Brasileira de Engenharia Agrícola e Ambiental, v. 5 , n. 2 , p. $211-215$

MOREIRA; C.S. \& ALLEONI, L.R.F. (2010). Adsorption of Cd, Cu, Ni and $\mathrm{Zn}$ in tropical soils under competitive and non-competitive systems. Science Agricola, v. 67, n. 3, p. 301-307.

MOREIRA, D.A.; MARTINEZ, M.A.; SOUZA, J.A.R.; MATOS, A.T.; REIS, C.; BARROS, F.M. (2010). Fatores de retardamento e coeficientes de dispersão-difusão de metais pesados em resíduos de construção civil e demolição. Revista Ambiente \& Água, v. 5, n. 2, p. 77-86.

NICOCHELLI, L.M.; NASCENTES, R.; LIMA, E.B.N.R.; SOARES, F.S.C. (2012). Sorção de potássio em amostras de solo submetidasà aplicação de vinhaça. Revista Brasileira de Engenharia Agrícola e Ambiental, v. 16, n. 7 , p. $754-760$

OLIVEIRA, E.M.M.; RUIZ, H.A.; FERREIRA, P.A.; ALVAREZ, V.H.; BORGES JÚNIOR, J.C.F. (2004). Fatores de retardamento ecoeficientes de dispersão-difusão de fosfato,potássio e amônio em solos de Minas Gerais. Revista Brasileira de Engenharia Agrícola e Ambiental, v. 8, n. 2/3, p. 196-203,

OLIVEIRA, F.J.S. \& JUCÁ, J.F.T. (2004). Acúmulo de metais pesados e capacidade de impermeabilização do solo imediatamente abaixo de uma célula de um aterro de resíduos sólidos. Engenharia Sanitária e Ambiental, v. 9, n. 3, p. 211-217.

OLIVEIRA, F.C. \& MATTIAZZO, M.E. (2001). Mobilidade de metais pesados em um latossolo amarelo distrófico tratado com lodo de esgoto e cultivado com cana-de-açúcar. Scientia Agricola, v. 58, p. 171-180,

OLIVEIRA, L.F.C.; CASTRO, M.L.L.; RODIGUES, C.; BORGES, J.D. (2010a). Adsorção e deslocamento do íon cádmio em solos do cerrado. Revista Brasileira de Engenharia Agrícola e Ambiental, v. 14, n. 8, p. 848-855.

OLIVEIRA, L.F.C.; CASTRO, M.L.L.; RODRIGUES, C.; BORGES, J.D. (2010b). Isotermas de sorção de metais pesados em solos do cerrado de Goiás. Revista Brasileira de Engenharia Agrícola e Ambiental, v. 14, n. 7, p. 776-782. 
OLIVEIRA, S. \&PASQUAL, A. (2004). Avaliação de parâmetros indicadores de poluição por efluente líquido de aterro sanitário. Engenharia Sanitária e Ambiental. v. 9, n. 3, p. 240-249.

PADILHA, A.C.M.; QUADROS, V.D.; MATTOS, P.; RODRIGUES, R.G. (2009). A equação tecnologia e a gestão de resíduos sólidos: uma análise do descarte de telefones celulares no município de Carazinho, RS. Revista Brasileira de Gestão Ambiental, v. 3, n. 1, p. 1-12.

PIAZ, J.F.D. \& FERREIRA, G.M.V. (2011). Gestão de resíduos sólidos domiciliares urbanos: o caso do município de Marau, RS. Revista de Gestão Social e Ambiental, v. 5, n. 1, p. 33-47.

PIERANGELI, M. A. P.; GUILHERME, L. R. G.; CURI, N.; COSTA, E. T. S.; LIMA, J. M.; MARQUES, J.J.G.S.M.; FIGUEIREDO, L.F.P. (2007). Comportamento sortivo, individual e competitivo, de metais pesados em latossolos com mineralogia contrastante. Revista Brasileira de Ciência do Solo, v. 31, p. 819-826.

PROCHNOW, T.R.; PROCHNOW, E.A.; LIBERMAN, B. (2009). Efeitos antrópicos sobre concentrações de metais alcalinos na região da microbacia do Arroio Araçá, Canoas, Rio Grande do Sul. Química Nova, v. 32, n. 7, p. 1782-1786.

RIBEIRO, D.R.; MARTINEZ,M.A.; MATOS, A.T.; RUIZ,H.A.; PARREIRAS, N.M.S.; CECON, P.R. (2011). Relação da velocidade de escoamento da solução e do comprimento da coluna de solo com os parâmetros de transporte de potássio em um latossolo e um neossolo. Revista Brasileira de Ciência do Solo, n. 35, p. 1907-1916.
SIMUNEK, J.; VAN GENUCHTEN, M.T.; SEJNA, M.; TORIDE, N.; LEIJ, F.J. The STANMOD computer software for evaluating solute transport in porous media using analytical solutions of the convection-dispersion equation, version 2.0.1 ed. Riverside: U.S. Salinity Lab., U.S. Dep. of Agric., 1999, 20p

SODRÉ, F.F.; LENZI,E.; SARAIVA DA COSTA, A.C. (2001) Utilização de modelos físico-químicos de adsorção no estudo do comportamento do cobre em solos argilosos. Química Nova, v. 24 n. 3 , p. $324-330$

SOUZA, R.S.; CHAVES, L.H.G.; FERNANDES, J.D. (2006). Adsorção de zinco e sua relação com características de solos do Estado da Paraíba. Revista Brasileira de Ciências Agrárias, v. 1, n.único, p. 1-6.

TAGLIAFERRO, G.V.; PEREIRA, P.H.F.; RODRIGUES, L.A.; SILVA, M.L.C.P. (2011). Adsorção de chumbo, cádmio e prata em óxido de nióbio hidratado preparado pelo método da precipitação em solução homogênea. Química Nova, v. 34, n. 1, p. 101-105.

VAN GENUCHTEN, M.T. \& WIERENGA, P.J. Solute dispersion coefficients and retardation factors. In: KLUTE, A. Methods of soil analysis: part $1-$ physical and mineralogical methods. Madison: Soil Science Society of America, 1986. p. 1025-1054.

VINHAL-FREITAS, I.C.; MALDONADO, A.C.D.; ALVARENGA, C.B. CAMARGO, R.; WENDLING, B. (2010). Adsorção e dessorção de metais no solo e coeficientes de isotermas de Freundlich e Langmuir Agropecuária Técnica, v. 31, n. 2, p. 153-163 